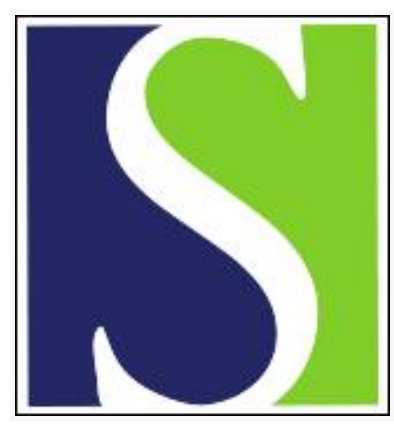

Scand J Work Environ Health 2004;30(4):334

https://doi.org/10.5271/sjweh.804

Issue date: Aug 2004

"You get what you ask for"-impact of the wording of questions on skin disease

by Meding B, Lidén C, Burström B

Affiliation: Occupational Dermatology, National Institute for Working Life. SE-113 91 Stockholm, Sweden. birgitta.meding@niwl.se

Key terms: letter to the editor; skin disease

This article in PubMed: www.ncbi.nlm.nih.gov/pubmed/15458019

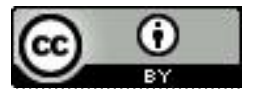




\section{"You get what you ask for"-impact of the wording of questions on skin disease}

Hand eczema is a skin disease that affects about $10 \%$ of the population of working age (1). It has noticeable consequences (eg, health care consumption, sick leave, change of work, and impairment of health-related quality of life) for both society and the individual (2). Furthermore, hand eczema is the most common occupational skin disease (2). The most frequent type of hand eczema is contact dermatitis caused by environmental factors like skin irritants or contact allergens. In public health surveys, it is thus important to include questions about skin disease, in particular hand eczema, to be able to study possible changes in occurrence. In this letter, we present our experience with a public health survey that produced remarkable results for a question on hand eczema and emphasize the importance of the wording of the question.

In Stockholm County, with about 1.8 million inhabitants, two different health surveys were performed using postal questionnaires. In an environmental health survey in 1997, questionnaires were sent to 15000 people aged 19-80 years (3-4), and in a public health survey in 1998, 5000 questionnaires were mailed to randomly selected persons aged 20-84 years (5). The response rates were $73 \%$ and $64 \%$, respectively.

In the environmental health survey, the wording of the question about hand eczema was "Have you had hand eczema on any occasion during the past 12 months?", and, in the public health survey, it was "Have you had any period of hand eczema or skin rash on any occasion during the past 12 months?" The intention was to use the same question. However, due to an unfortunate technical mishap, the wording of the question in the public health survey was not the same. "Yes" answers were obtained from $8 \%$ (males $6 \%$, females $10 \%$ ) of the respondents in the environmental health survey and from $31 \%$ (males $32 \%$, females $26 \%$ ) of the respondents in the public health survey.

The question used in the environmental health survey had been previously used in several Swedish studies, and the reported 1-year prevalence of hand eczema was in agreement with previous experience (1). A validation of the question has shown a sensitivity of 53$59 \%$ and a specificity of $96-99 \%$ (6).

It is impossible to know what the respondents included in the concept "rash" as used in the public health questionnaire. Probably several of the most common skin diseases besides hand eczema were also reported, diagnoses like psoriasis, urticaria, atopic dermatitis, seborrhoic dermatitis, acne, rosacea, tinea, hypostatic eczema, and some skin tumors. The occurrence of skin disease (all diagnoses) in the general population has been estimated to be about $30 \%$ (7), thus similar to the result for the question used in the public health survey.

This example illustrates that the exact wording of a question is of utmost importance if results are to be interpreted properly and consequently used for different purposes (eg, to follow trends and to estimate the effects from preventive strategies). For questions about occupational skin disease and exposure, a new questionnaire tool was recently developed (8). When a questionnaire is being designed, advice should be sought from persons with expert knowledge in the field on what the question is intended to cover; in the case of skin disease, the person should be a dermatologist experienced in epidemiology.

\section{References}

1. Meding B, Järvholm B. Hand eczema in Swedish adultschanges in prevalence between 1983 and 1996. J Invest Dermatol 2002;118:719-23.

2. Diepgen TH. Occupational skin-disease data in Europe. Int Arch Occup Environ Health 2003;76:331-8.

3. Stockholm's läns landsting [Stockholm County Council]. Miljöhälsorapport 1998 [Environmental health report 1998]. Stockholm: Stockholm's läns landsting; 1998.

4. Meding B, Lidén C, Berglind N. Self-diagnosed dermatitis in adults: results from a population survey in Stockholm. Contact Dermatitis 2001;45:341-5.

5. Stockholm's läns landsting [Stockholm County Council]. Folkhälsorapport 1999 [Occupational health report 1999]. Stockholm: Stockholm: Stockholm's läns landsting; 1999.

6. Meding B, Barregård L. Validity of self-reports of hand eczema. Contact Dermatitis 2001;45:99-103.

7. Meding B. Normal standards for dermatological health screening at places of work. Contact Dermatitis 1992;27:269-70.

8. Susitaival P, Flyvholm M-A, Meding B, Kanerva L, Lindberg M, Svensson $\AA$, et al. Nordic occupational skin questionnaire (NOSQ-2002): a new tool for surveying occupational skin diseases and exposure. Contact Dermatitis 2003;49:70-6.

Birgitta Meding, MD, ${ }^{1}$ Carola Lidén, MD, ${ }^{2}$ Bo Burström, $\mathrm{MD}^{3}$

1 Occupational Dermatology, National Institute for Working Life, Stockholm, Sweden.

2 Occupational and Environmental Dermatology, Stockholm County Council and Karolinska Institutet, Stockholm, Sweden.

3 Social Medicine, Stockholm County Council and Karolinska Institutet, Stockholm, Sweden.

Correspondence to: Dr Birgitta Meding, Occupational Dermatology, National Institute for Working Life, SE-113 91 Stockholm, Sweden. [E-mail: birgitta.meding@niwl.se] 